\title{
Perioperative Duloxetine and Etoricoxibto improve postoperative pain after lumbar Laminectomy: a randomized, double-blind, controlled study
}

\author{
Josef Zekry Attia* and Haidy Salah Mansour
}

\begin{abstract}
Background: Duloxetine, Etoricoxib and opioid are of the commonly administered drugs in Lumbar laminectomy. The aim of this study is to assess the effect of perioperative use of Duloxetine in combination with Etoricoxib on postoperative pain and opioid requirements.

Methods: One hundred twenty patients with ASA physical status were enrolled with age between 18 and 70 years. Patients were divided randomly into four groups of 30 patients: group P received placebo, group E received etoricoxib $120 \mathrm{mg}$, group D received duloxetine $60 \mathrm{mg}$ and group D/E received duloxetine $60 \mathrm{mg}$ capsules and etoricoxib $120 \mathrm{mg} ; 1 \mathrm{~h}$ before surgery and $24 \mathrm{~h}$ after.

Results: Neither Duloxetine nor etoricoxib individually had effect on pain with movement, while their combination revealed a significant reduction in pain scores over the entire postoperative period at rest and on movement. Etoricoxib showed a significant decrease in pain at all times at rest when compared with group $P$, while it showed significant pain decrease only at 0,2 and $4 \mathrm{~h}$ when compared with group D. On the other hand duloxetine alone showed significant decrease in pain at rest at $24 \mathrm{~h}$ and $48 \mathrm{~h}$ when compared with group P. ConcerningMorphine requirement after 24 h.; it wassignificantly lower in the D/E group in comparison with groups P, E and D. It should be noted also that there was a significant decrease morphine requirement in both groups $E$ and $D$.
\end{abstract}

Conclusion: The perioperative administration of the combination of etoricoxib and duloxetine improved analgesia and reduced opioid consumption without significant side effects.

Trial registration: ISRCTN48329522. 17 June 2017

Keywords: Postoperative pain, Analgesia, Duloxetine, Etoricoxib, Lumbar Laminectomy

\section{Background}

Postoperative pain is mediated by different mechanisms at multiple neural sites. Thus, multimodal analgesics can reduce the postoperative pain [1]. Although Opioids are considered the analgesics of choice to treat moderate to severe pain, their use carries the risk of side effects and hyperalgesia [2]. Multimodal analgesia can be achieved by combining different analgesics and different methods of administration, to provide better analgesia synergistically compared with conventional analgesia [3].

\footnotetext{
* Correspondence: josefzekry2@yahoo.com

Departments of Anesthesiology and I.C.U Al-Minia University, Faculty of Medicine, Minia University, Minia 61111, Egypt
}

Therefore,lower doses for each drug can be provided with fewer overall side-effects obtained from individual compounds [4].

Recently, antidepressants such as duloxetine, a selective serotonin and norepinephrine reuptake inhibitor (SSNRI), have accomplished pain relief in persistent and chronic pain as in fibromyalgia, postherpetic neuralgia, diabetic neuropathy [5], osteoarthritis and musculoskeletal pain [6]. Theanalgesic effect of duloxetine is attributed to its ability to enhance both serotonin and norepinephrine neurotransmission in descending inhibitory pain pathways. [7]. Moreover, some studies have promoted its use to improve the quality of recovery after 
surgery and reduce the acute postoperative pain after knee replacement surgery [8], mastectomy [9], hysterectomy [10], and after spine surgery [11]. In addition it can improve postoperative quality of recovery through mood improvement that can be helpful in the postoperative period [12].

Another group of analgesics isthe non-steroidal antiinflammatory drugs (NSAIDs) which are used for acute pain management. It has pain-relieving, antipyretic, and anti-inflammatory properties [13]. It's thought that its analgesic effect is caused by suppression of cyclooxygenase (COX) thus it inhibits the synthesis of PGs [14]. However, beingnonselective in inhibition of COX1 and COX2; several adverse effects can appear [15]. It is thought that the therapeutic activity of NSAIDs is due to the inhibition of COX-2, whereas the adverse effects results from inhibition of COX-1 [16]. Thus, many studies show that the selective COX-2 inhibitors have a great role in reducing the postoperative pain and reducing the dose of postoperative opioid consumption [17-19].

Etoricoxib is more highly selective of COX-2 over COX-1 than celecoxib [20], and characterized bylonger duration of action ranging 22-24 h. In addition, it is absorbed rapidly after oral intake so the peak plasma concentrations are reached after $1 \mathrm{~h}$ [21]. It was examined preoperatively by different studies and revealedefficacy in providing postoperative analgesia after abdominal [17], laparoscopic [19], gynecological [22] and orthopedic procedures $[18,23]$. However, additive or synergistic interactions can be detected when two analgesics are administered together at the same time [24]. In cases of synergistic interaction, we can use smaller doses of each drug to achieve good analgesia with fewer adverse effects derived from individual compounds [4].

The main objective of the present study was to examine perioperativelythe analgesic efficacy with the combination of duloxetine and etoricoxib on postoperative pain and itsopioid-sparing properties when given as part of a multimodal pain strategy in patients undergoing surgery on the lumbar spine. In addition toevaluating the patient's satisfaction and the adverse effects related to the combination of both medications.

\section{Methods}

After institutional Ethics Committee approval, this prospective double-blind, randomized, controlled study was started in November 2015 at the department of anesthesia and intensive care unit; El- Minia University Hospital. The study involved 120 adult patients of both genders aging between 18 and 70 years of age with an ASA physical status of I, II and III,who were scheduled for single level lumbar spinal disc prolapse surgery. All patients gave written informed consent.
Exclusion criteria involved patients with history of allergic reaction to any of the study drugs, history of drug or alcohol abuse, and abnormal renal or liver function tests. Patients using antidepressants had to stop taking them 2 weeks before surgery. Also, Patients with previous cervical surgeries, psychiatric disorders and patients receiving opioid analgesic medications within $24 \mathrm{~h}$ preoperatively were excluded.

We asked the patients to visit the outpatient clinic 1 day before surgery for assessment and performing laboratory investigations. We also explained to them the study protocols, including analgesic administration and the11-point numeric rating scale (NRS) where 0 being 'no pain' and '10' being the maximal worst pain [25].

\section{Study design}

The patients admitted to the hospital were randomized according to the computer-generated random numbers with closed-sealed envelopes into one of the four groups 30 patients each. The study medications were prepared by the pharmacy of the hospital and given to the patients by an investigator not involved in the study. They were duloxetine $60 \mathrm{mg}$ capsules (Cymbalta; Eli Lilly \& Company, Indiana, USA), etoricoxib $60 \mathrm{mg}$ film coated tablets (Arcoxia; Merck Sharp \&Dohme Limited, Hertford road, Hoddesdon, Hertfordshire, UK), and placebo capsules that matched the duloxetine capsules or etoricoxib tablet in color and size. All drugs were given $1 \mathrm{~h}$ before surgery and repeated after $24 \mathrm{~h}$.

1. The Group P (Placebo) received placebo capsule + two placebo tablet

2. The Group E (etoricoxib) received placebo capsule + two etoricoxib tablet $60 \mathrm{mg}$

3. The Group D (duloxetine) received duloxetine capsule $60 \mathrm{mg}+$ two placebo tablet

4. The Group DC (duloxetine + etoricoxib) received duloxetine $60 \mathrm{mg}$ capsules + two etoricoxib tablets $90 \mathrm{mg}$

On arrival to the operating room,standard intraoperative monitoring includedelectrocardiogram (ECG), heart rate $(\mathrm{HR})$, mean arterial blood pressure (MABP), oxygen saturation (SPO2) and end tidal $\mathrm{CO} 2$ were recorded and subsequent measurements were recorded every $5 \mathrm{~min}$ till the end of the operation using a multiparameter monitor (Mindray iMEC12, Hi-tech industrial Park,Nanshan, Shenzhen, china).

General anesthesia was induced by $(1.5 \mu \mathrm{g} / \mathrm{kg})$ fentanyl IV, $(2 \mathrm{mg} / \mathrm{kg})$ propofol IV, and endotracheal intubation was performed with $(0.5 \mathrm{mg} / \mathrm{kg}) \mathrm{IV}$ atracurium. Maintenance of anesthesia was done through inhalation of a mixture of oxygen $(3 \mathrm{~L} / \mathrm{min})(1-2 \%)$ isoflurane and $(0.05 \mathrm{mg} / \mathrm{kg})$ 
atracurium as intermittent dose of muscle relaxant to ensure proper muscle relaxation during the procedure.

An anesthetist who was blinded to the groups took all the measurements. Their goal was to adjust the anesthetics concentration to keep the heart rate and blood pressure within $20 \%$ of the base line value throughout the anesthesia period.At the end of surgery, the first dose of paracetamol $1000 \mathrm{mg} / 100 \mathrm{ml}$ intravenously (Medalgesic; ARABCOMED, Cairo, Egypt) was given to all patients before extubation. Then, reversal of neuromuscularblockade was performed with atropine $(0.01 \mathrm{mg} / \mathrm{kg})$ and neostigmine $(0.05 \mathrm{mg} / \mathrm{kg})$ given intravenously. After tracheal extubation, patients were transferred to the postanesthetic care unit (PACU) where vital parameters were recorded every $1 / 2 \mathrm{~h}$ till complete recovery.

During the first $48 \mathrm{~h}$, a standard analgesic regimen of paracetamol $1 \mathrm{~g}$ was given intravenously every $6 \mathrm{~h}$ to all patients. In addition, pain assessment in the ward was performed by nurses every $2 \mathrm{~h}$ and titrated doses of morphine ( $2 \mathrm{mg}$ bolus at $10 \mathrm{~min}$ intervals) were given if patients reported pain (NRS was $\geq 3$ ).

The postoperative data were collected by a senior resident (blinded to the study). The NRS pain scores was recorded at $30 \mathrm{~min}$ after the end of anesthesia (time $=0$ ), all patients were able to answer questions and to rate their pain score at the end of 2, 4, 6, 12, 24 and 48 h postoperatively in the ward. Pain assessments were done at rest and with movement (after the patient completed a $90^{\circ}$ logroll while in bed).

The time to first rescue analgesic, total morphine consumption at (24 h and $48 \mathrm{~h}$ ) and the presence of side effects, such as headache, rash, nausea, vomiting, dizziness and drowsiness were recorded. The severity of postoperative nausea and vomiting (PONV) was graded on a fourpoint ordinal scale (I) not at all, (II) sometimes, (III) often or most of the time, and (IV) all of the time with vomiting [26]. Ondansetron, a rescue antiemetic, (4 mg) IV was given to all patients with PONV score more than II.

Patient satisfaction was measured at $24 \mathrm{~h}$ post-operatively using a numerical score of $1-4(1=$ poor, $2=$ fair, $3=$ good, $4=$ very good).

After the study was completed, randomization and allocation were revealed for data analysis.Sample size estimation was made based on morphine consumption in a retrospective sample of 50 patients who was undergoing spinal surgery in our department. The sample size was calculated using power analysis $(\alpha=0.05, \beta=0.8)$ to detect $50 \%$ difference in morphine consumption between groups at $48 \mathrm{~h}$ post-surgery and was found to require at least 24 patients per group. Thus, we decided to include 30 patients per group to allow for possible drop-out.

\section{Statistical analysis}

Data were presented as median (with inter-quartile range) or mean \pm standard deviation. While qualitative data were presented as number (frequency distribution). Data such as ASA grade, sex distribution, Patient's satisfaction, and Side effects were inferred by Chi-square test and fisher's exact test. Data such as age, weight, height, mean duration of surgery, time of first rescue analgesic and total morphine requirement were inferred by ANOVA and post hoc Bonferroni test was used for in intergroup comparison. Differences in NRS scores were analyzed using the kruksal-wallis-test and the Mann-Whitney U-test was used for subsequent pairwise comparisons. The $p$-value of less than 0.05 was considered significance.

\section{Results}

From November 1, 2015 to March 1, 2017, 131 consecutive patients who met the inclusion criteria were allocated for the study (Fig. 1). Eleven patients refused to participate. Therefore, 120 patients were randomized and included in the study. Characteristics of patients and surgical procedures for each group (Table 1) showed no significant differences between the groups.

\section{The morphine requirement}

The time to first rescue analgesic was significantly prolonged in $(\mathrm{D} / \mathrm{E})$ when compared with group $\mathrm{D}$, group $\mathrm{E}$ and group P.There was a significant prolongation when groups $\mathrm{E}$ and $\mathrm{D}$ were compared with group $\mathrm{P}$ respectively with no significant difference between group $E$ and group D (Fig. 2).

The morphine requirement at $24 \mathrm{~h}$ was statistically different between the four groups.

. There were significantly increased morphine requirements in the $\mathrm{P}$ group compared with $\mathrm{E}, \mathrm{D}$ and $\mathrm{D} / \mathrm{E}$ groups and significantly increased in $\mathrm{E}$ and $\mathrm{D}$ groups respectively when compared with $\mathrm{D} / \mathrm{E}$ group with no significant difference between group $\mathrm{E}$ and group $\mathrm{D}$ (Fig. 3). At $48 \mathrm{~h}$, total morphine requirement were still significantly increased in the $\mathrm{P}$ group compared with all groups with significant increases in both $\mathrm{E}$ and $\mathrm{D}$ groups when compared with $\mathrm{D} / \mathrm{E}$ group with no significant difference between group $E$ and group D (Fig. 4). But it was still significantly lower in the three groups at $48 \mathrm{~h}$ post-surgery when compared with those required at $24 \mathrm{~h}$.

\section{The pain score}

With regard to pain scores at rest all time points, the duloxetine/etoricoxib (D/E) group had significantly lower pain scores when compared to placebo group P, while when it compared to etoricoxib group E, also when compared $\mathrm{D} / \mathrm{E}$ with duloxetine group $\mathrm{D}$ (Table 2).

The pain score in group E was significantly decreased at most time periods when compared to group $\mathrm{P}$ at 0,2 and $4 \mathrm{~h}$ at rest when compared with group $\mathrm{D}$. The pain score in group D was significantly decrease at 24 and $48 \mathrm{~h}$ compared to group P (Table 2). 


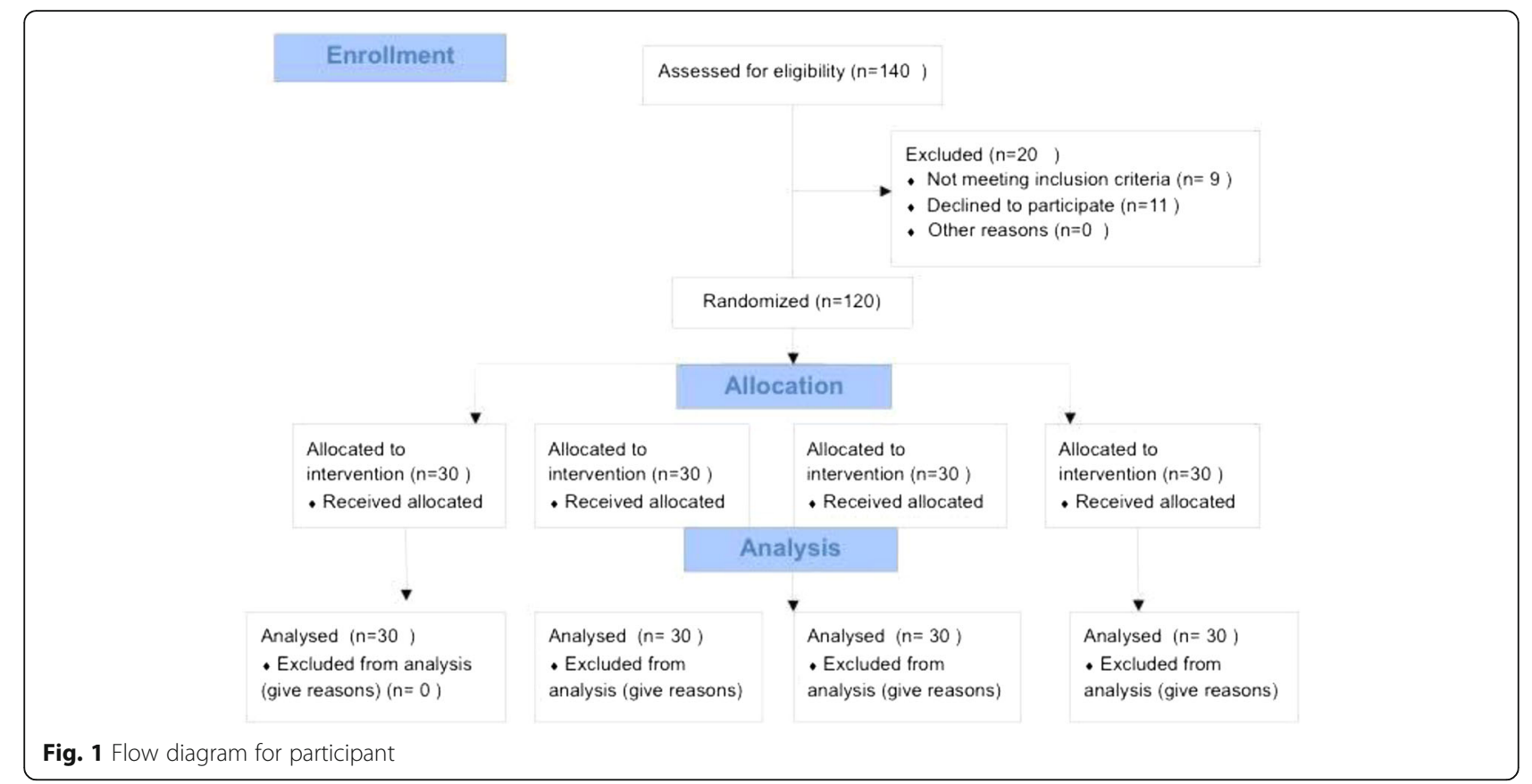

While on movement pain was significantly decreased in $\mathrm{D} / \mathrm{E}$ at all times when compared togroup $\mathrm{P}$ and when it compared to group $\mathrm{E}$ and when it compared to group D with no significant difference between other groups on movement (Table 3).

\section{Patients' satisfaction}

The percentage of patients' satisfaction (excellent) shows significant differences between the four groups at $24 \mathrm{~h}$ (Table 4) with no significant differences between the three groups at $48 \mathrm{~h}$.

The most common adverse effect expected by patients in the study was nausea and vomiting grades III and IV. There was a significant increase in percentage of patients in group P (43.3\%) when compared with group
$\mathrm{D} / \mathrm{E}(16.6 \%)$ and who reported nausea and vomiting. All complained patients responded to i.v.ondansetron. No statistically significant differences were noted between groups with regard to adverse effects (Table 5).

\section{Discussion}

To our knowledge, there have been no studies evaluating the combination of selective COX-2 inhibitors (etoricoxib) and a selective serotonin and norepinephrine reuptake inhibitor (SNRI) (duloxetine) after spine surgery. Therefore, we decided in this study to use this regimen based on the results of previous clinical trials. A number of reports have demonstrated success with either the use of etoricoxib [18-20,23] or duloxetine [8-11] with less reported success about the efficacy of their combination

Table 1 Characteristics of patients and surgical procedures in the four groups

\begin{tabular}{|c|c|c|c|c|c|}
\hline $\begin{array}{l}\text { Group } \\
\text { Variable }\end{array}$ & $\begin{array}{l}\text { Group (P) } \\
(n=30)\end{array}$ & $\begin{array}{l}\text { Group (E) } \\
(n=30)\end{array}$ & $\begin{array}{l}\text { Group (D) } \\
(n=30)\end{array}$ & $\begin{array}{l}\text { Group (D/E) } \\
(n=30)\end{array}$ & $P$ value \\
\hline Age (years) & $46.50 \pm 8.74$ & $45.26 \pm 7.50$ & $48.36 \pm 9.80$ & $47.50 \pm 10.14$ & 0.455 \\
\hline Male/Female (n) & $15 / 15$ & $17 / 13$ & $18 / 12$ & $16 / 14$ & 0.471 \\
\hline Weight (kg) & $81.23 \pm 13.24$ & $82.53 \pm 12.90$ & $80.60 \pm 13.37$ & $78.83 \pm 16.78$ & 0.794 \\
\hline Height (cm) & $167.46 \pm 8.50$ & $165.53 \pm 7.71$ & $165.40 \pm 8.21$ & $165.00 \pm 9.63$ & 0.478 \\
\hline \multicolumn{6}{|l|}{ ASA (n) } \\
\hline । & 18 & 18 & 17 & 15 & 0.36 \\
\hline$\|$ & 7 & 6 & 9 & 10 & 0.42 \\
\hline III & 5 & 6 & 4 & 5 & 0.23 \\
\hline Duration of surgery (min) & $109.9 \pm 10.8$ & $115.7 \pm 9.8$ & $113.2 \pm 13.7$ & $117.8 \pm 9.7$ & 0.65 \\
\hline
\end{tabular}

Data are presented as Mean \pm SD or number $(n)$

Placebo group (P), Etoricoxib group (E), Duloxetine group (D), Duloxetine/Etoricoxib group (D/E). Data were analyzed using ANOVA test with post hoc test (Bonferroni) and chi square test 


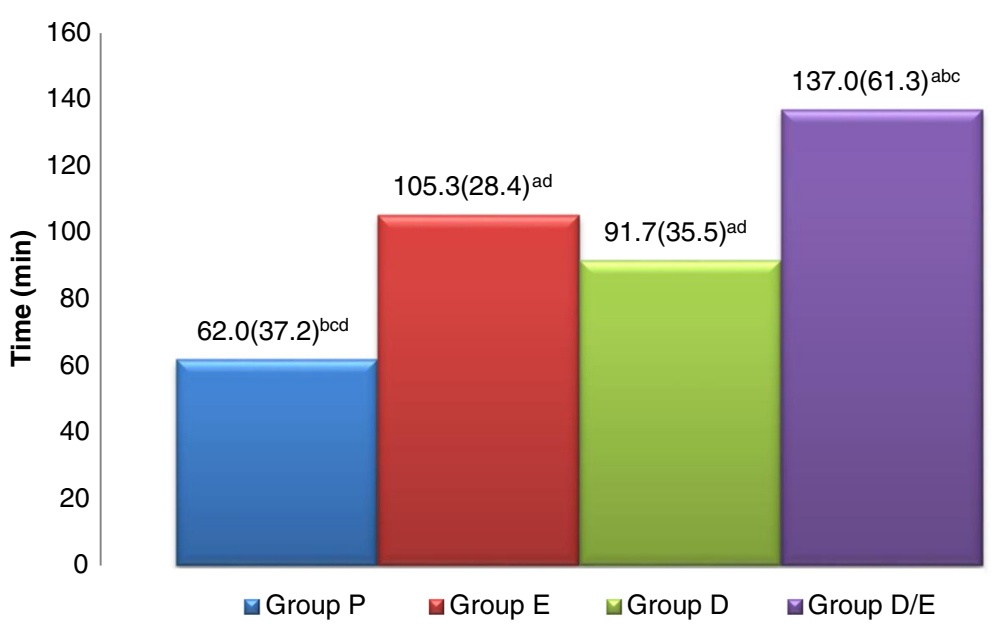

Fig. 2 Time to morphine administration after surgery in the four groups as Mean(SD). Placebo group (P), etoricoxib (E), Duloxetine (D), Duloxetine/etoricoxib (D/E). a: when compared with P group. b: when compared with E group. c: when compared with $D$ group. d: when compared with E/D group

in humans. Sun et al., [24] reported that pretreatment with an intraperitoneal injection of duloxetine and celecoxib produced synergistic analgesia and could attenuate pain in mice $1 \mathrm{~h}$ after formalin injection.

Duloxetine is a selective SNRI that is prescribed for treatment of depression and anxiety disorders [27]. It is also efficacious in treating pain in diabetic neuropathy and fibromyalgia [6]. The mechanism of its analgesic action could be explained by a combined central and peripheral pain modulating role [28] through the effect of serotonin and norepinephrine on descending inhibitory pain pathways in the brain and spinal cord [29] and activation of some cerebral prefrontal areas [5]. Also it has a antinociceptive effect through $\mathrm{Na}+$ channel blocks [30] with antihyperalgesic effects through the inhibition of the neuronal cell firing resulting from peripheral injury [31]. Therefore,duloxetine has a great role in management of neuropathic pain and reducing postoperative pain. In addition, it may improve the depression and anxiety that are common during the perioperative period [32].

In this randomized study, despite the fact that each of the two drugs separately could not produce analgesia during movement, their combination induced significant reduction in pain score at rest and on movement over the study time points and also improved patients satisfaction at $24 \mathrm{~h}$ postoperatively. Although, each of the drugs separately were able to prolong the duration of first rescue to analgesia and reduce postoperative morphine consumption, the combination also remained



Fig. 3 Morphine requirements at $24 \mathrm{~h}$ in the four groups as mean (SD). Placebo group (P), etoricoxib (E), Duloxetine (D), Duloxetine/etoricoxib (D/E). a: when compared with P group. b: when compared with E group. c: when compared with D group. d: when compared with E/D group 


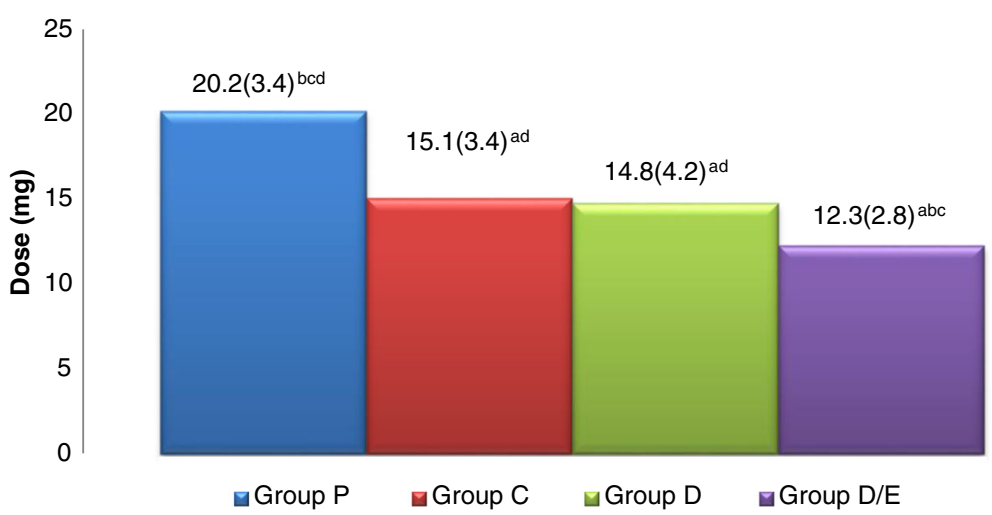

Fig. 4 Morphine requirements at $48 \mathrm{~h}$ in the four groups as mean (SD). Placebo group (P), etoricoxib (E), Duloxetine (D), Duloxetine/etoricoxib (D/E). a: when compared with P group. b: when compared with E group. c: when compared with D group. d: when compared with E/D group

significantly effective when compared with them. Therefore, this may accelerate the rehabilitation and reduce postoperative morbidity [33].

The analgesic effect of antidepressants is typically seen after 7 to 14 days, therefore It's commonly used for chronic pain [34]. However, some investigators use duloxetine immediately preoperatively for acute pain management $[8,10]$. In our study, we demonstrated that two doses of $(60 \mathrm{mg})$ duloxetine $1 \mathrm{~h}$ before surgery and after $24 \mathrm{~h}$ could reduce opioid consumption with no significant effect on early postoperative pain score. Our result was comparable to Ho et al. [8] who assessed the use of two doses of duloxetine on pain scores postoperatively following knee arthroplasty. Also, Castro Alves et al. [10] examined the same regimen in patients undergoing abdominal hysterectomies and recently, Bedin et al. [11] performed the same assessment after spine surgery. On our study, the first dose of duloxetine was given $1 \mathrm{~h}$ before surgery. In contrast, Nasr [9] gave the first dose of duloxetine $60 \mathrm{mg} 2$ days before surgery in patients

Table 2 Pain scores (NRS) at rest in the four groups

\begin{tabular}{|c|c|c|c|c|c|}
\hline oup & $\begin{array}{l}\text { Group (P) } \\
(n=30)\end{array}$ & $\begin{array}{l}\text { Group (E) } \\
(n=30)\end{array}$ & $\begin{array}{l}\text { Group (D) } \\
(n=30)\end{array}$ & $\begin{array}{l}\text { Group (D/E) } \\
(n=30)\end{array}$ & \\
\hline $\mathrm{Oh}$ & $5(4-5.25)^{b d}$ & $4(3-4)^{\text {acd }}$ & $4(3-5)^{b d}$ & $3(3-4)^{a b c}$ & 001 \\
\hline $2 \pi$ & $4(3-5)$ ind & $3(3-4)$ acd & $4(3-5)^{b d}$ & $3(3-3)^{a b c}$ & 0.0001 \\
\hline $4 \mathrm{~h}$ & $4(3-5)^{b d}$ & $3(3-4)$ acd & $3(3-4) b d$ & $2(2-3)^{a b c}$ & 0.0001 \\
\hline $6 \mathrm{~h}$ & $3(3-4)^{b d}$ & $3(2-4)^{a d}$ & $2.5(2-3)^{d}$ & $2(1-3)^{a b c}$ & 0.0001 \\
\hline 11 & $3(3-3)^{b d}$ & $3(2-3)^{\text {ad }}$ & $3(2-3)^{d}$ & $2.5(1-3) a b c$ & م \\
\hline $24 \mathrm{~h}$ & $3(2-3)^{b c d}$ & $2(2-3)^{a d}$ & $2.5(2-3)^{\mathrm{ad}}$ & $2(1-2)^{a b c}$ & 0.0001 \\
\hline $48 \mathrm{~h}$ & $3(2-3)^{b c d}$ & $2(2-3)^{a d}$ & $2(2-3)^{a d}$ & $2(0.75-2)^{a b c}$ & 0.0001 \\
\hline
\end{tabular}

Placebo group (P), Etoricoxib (E), Duloxetine (D), Duloxetine/Etoricoxib (D/E) Data are presented as median (interquartile range). Data were analyzed by Mann-Whitney U-test and kruksal-wallis test and $P<0.05$ is considered significant

a: when compared with $P$ group

b: when compared with $E$ group

c: when compared with D group

$\mathrm{d}$ : when compared with D/E group undergoing mastectomy and recorded lower pain scores in the duloxetine group compared to a control group at the study period.

Although etoricoxib has been shown to have significant analgesic efficacy during pain at rest when compared to thecontrol group in our results, there was no effect on pain score on movement. These results resembled those of Rawal et al. [35] where they evaluated the effect of etoricoxib (90 or $120 \mathrm{mg}$ ), versus ibuprofen (1800 $\mathrm{mg}$ ) on postoperative pain following knee replacement and concluded that etoricoxib(90 and $120 \mathrm{mg}$ ) was significantly effective in reducing pain at rest and also reduced morphine consumption when compared to placebo with no significant effect on movement. Also Lierz et al. [23] used $120 \mathrm{mg}$ of etoricoxib or placebo $1 \mathrm{~h}$ before induction of general anesthesia in knee arthroscopy surgery. They recorded similar results, showing reduction in pain only at rest and reduction in morphine consumption.

Opioids are considered the drug of choice for management of postoperative pain but it is difficult to induce an

Table 3 Pain scores (NRS) on movement in the four groups

\begin{tabular}{|c|c|c|c|c|c|}
\hline $\begin{array}{l}\text { Group } \\
\text { Variable }\end{array}$ & $\begin{array}{l}\text { Group (P) } \\
(n=30)\end{array}$ & $\begin{array}{l}\text { Group (E) } \\
(n=30)\end{array}$ & $\begin{array}{l}\text { Group (D) } \\
(n=30)\end{array}$ & $\begin{array}{l}\text { Group (D/E) } \\
(n=30)\end{array}$ & value \\
\hline$\overline{\mathrm{Oh}}$ & $5(5-6.25)^{d}$ & $5(5-6)^{d}$ & $5(5-6)^{d}$ & $5(4.5 .25)^{a b c}$ & 0.013 \\
\hline fter $2 \mathrm{~h}$ & $5(5-6)^{d}$ & $5(4-6)^{d}$ & $(5-6)^{d}$ & $(4-5)^{a b c}$ & 02 \\
\hline fter $4 \mathrm{~h}$ & $4(4-5)^{d}$ & $4(4-5)^{d}$ & $4(4-5)^{d}$ & $4(3-4) a b c$ & 0.019 \\
\hline fter $6 \mathrm{~h}$ & $4(3-5)^{d}$ & $4(3-5)^{d}$ & $4(4-5)^{d}$ & $4(3-4) a b c$ & 0.007 \\
\hline fter $12 \mathrm{~h}$ & $4(3-5)^{d}$ & $4(3-4)^{d}$ & $4(3-4.25)^{d}$ & $3(3-4) a b c$ & 0 \\
\hline After $24 \mathrm{~h}$ & $4(3-5)^{d}$ & $4(3-4.25)^{d}$ & $4(3-4)^{d}$ & $3(2.75-4) a b c$ & 0.059 \\
\hline fter $48 \mathrm{~h}$ & $3.5(3-4)^{d}$ & $3(3-4)^{d}$ & $3.5(3-4)^{d}$ & $3(2.75-4) a b c$ & $0.04 \varsigma$ \\
\hline
\end{tabular}

Placebo group (P), Etoricoxib (E), Duloxetine (D), Duloxetine/Etoricoxib (D/E) Data are presented as median (interquartile range). Data were analyzed by Mann-Whitney U-test and kruksal-wallis test and $P<0.05$ is considered significant. a: when compared with P group

b: when compared with $\mathrm{E}$ group

c: when compared with D group

$\mathrm{d}$ : when compared with D/E group 
Table 4 Patient's satisfaction in the four groups at $24 \mathrm{~h}$

\begin{tabular}{llllll}
\hline $\begin{array}{l}\text { Group } \\
\text { Patient satisfaction }\end{array}$ & $\begin{array}{l}\text { Group(P) } \\
(n=30)\end{array}$ & $\begin{array}{l}\text { Group(E) } \\
(n=30)\end{array}$ & $\begin{array}{l}\text { Group(D) } \\
(n=30)\end{array}$ & $\begin{array}{l}\text { Group(D/E) } \\
(n=30)\end{array}$ & $p$ \\
\hline ExEellent & $9(30 \%)$ & $12(40 \%)$ & $11(36.7 \%)$ & $21(63.3 \%)^{*}$ & 0.004 \\
Good & $9(30 \%)$ & $10(33.3 \%)$ & $9(30 \%)$ & $5(23.3 \%)$ & 0.237 \\
Fair & $8(26.7 \%)$ & $5(16.5 \%)$ & $6(20 \%)$ & $2(6.7 \%)$ & 0.069 \\
Poor & $4(13.3 \%)$ & $3(10 \%)$ & $3(10 \%)$ & $2(6.7 \%)$ & 0.933 \\
\hline
\end{tabular}

Data are presented as number (\%). Data were analyzed using chi square. Placebo group (P), Etoricoxib (E), Duloxetine (D), Duloxetine/Etoricoxib (D/E). $P$ $<0.05$ is considered significant

${ }^{*} P=0.016$ when compare with $\mathrm{P}$

optimum analgesia without significant side effects [36]. Therefore, we suggest in our study that short-term duloxetine treatment in combination with etoricoxib may be a good adjuvant for decreasing the need for opioids in order to alleviate postoperative pain without significant adverse effects. In our results there were 13 patients complaining of nausea and vomiting in the placebo group with significant difference when compared to $\mathrm{D} / \mathrm{E}$ group. There were no incidences of other adverse effects, such as sedation, dizziness, somnolence, pursuits or headache.

In this study we evaluate the acute postoperative pain not the chronic pain examined in previous studies $[8,9,37]$ because our study was on a group of patients complaining from chronic back ache with high incidence of postoperative failed back pain syndromewith multifactorial conditions which may affect up to 10 to $40 \%$ of patients [38].

\section{Conclusion}

The present study demonstrates that the perioperative administration of the duloxetine/etoricoxib combination reduces postoperative pain, beside the need for morphine at 24 and $48 \mathrm{~h}$ after lumbar spine surgery, and the opioidrelated side effects more effectively than either drug alone. Duloxetine/etoricoxib combination may thus be a useful adjuvant to be used along with opioid as part of a multimodal analgesia in the acute postsurgical setting.

Table 5 Side effects in the four groups

\begin{tabular}{llllll}
\hline $\begin{array}{l}\text { Group } \\
\text { Side effect }\end{array}$ & $\begin{array}{l}\text { Group(P) } \\
(n=30)\end{array}$ & $\begin{array}{l}\text { Group(E) } \\
(n=30)\end{array}$ & $\begin{array}{l}\text { Group(D) } \\
(n=30)\end{array}$ & $\begin{array}{l}\text { Group(D/E) } \\
(n=30)\end{array}$ & $p$ \\
\hline $\begin{array}{l}\text { PONV (\%) } \\
\text { IIII\&IV }\end{array}$ & $13(43.3 \%)^{*}$ & $7(23.3 \%)$ & $7(23.3 \%)$ & $5(16.6 \%)$ & 0.027 \\
Somnolence & $1(3.3 \%)$ & $1(3.3 \%)$ & $2(6.7 \%)$ & $3(10 \%)$ & 0.225 \\
Pruritus & $5(16.7 \%)$ & $4(13.3 \%)$ & $3(10 \%)$ & $3(10 \%)$ & 0.390 \\
Dizziness & $1(3.3 \%)$ & $2(6.7 \%)$ & $4(13.3 \%)$ & $3(10 \%)$ & 0.239 \\
Headache & $6(20 \%)$ & $3(10 \%)$ & $5(16.7 \%)$ & $4(13.3 \%)$ & 0.907 \\
\hline
\end{tabular}

Data are presented as number (\%). Data were analyzed using chi square test and fisher's exact test. Placebo group (P), Etoricoxib (E), Duloxetine (D), Duloxetine/Etoricoxib (D/E). $P<0.05$ is considered significant. ${ }^{*} P=0.024$ when compare $\mathrm{P}$ and $\mathrm{D} / \mathrm{E}$
Concerning limitations to our study, there are some to be applied. First it is not possible to prove that the combination of duloxetine and etoricoxib has more than just an additive effect because we did not make a full dose-response study nor associated ED50s. The second limitation of our study is that we evaluated a possible effect of duloxetine on acute postsurgical pain alone and not on the chronic one.

\section{Abbreviation}

COX: Cyclooxygenase; ECG: Electrocardiogram; HR: Heart rate; MABP: Mean arterial blood pressure; NRS: Numeric rating scale; NSAIDs: Non-steroidal antiinflammatory drugs; SPO2: oxygen saturation; SSNRI: Selective serotonin and norepinephrine reuptake inhibitor

\section{Acknowledgments}

We thank all member of anesthesiology department, faculty of medicine. Minia University, Egypt.

\section{Funding}

This research received no specific grant from any funding agency in the public.

Availability of data and materials

The data are available upon request to the corresponding author.

\section{Authors' contributions}

JZA preformed study design and conduction, data collection and analysis, and revising the manuscript. All authors read and approved the final manuscript. HSM preformed study design and conduction, data collection and analysis, preparation of the manuscript, and writing up of the first draft.

\section{Ethics approval and consent to participate}

The study was approved by research ethics of Al- Minia University hospital, Faculty of medicine, Al- Minia University. The written informed consent was obtained from patients).

\section{Consent for publication}

Not applicable.

\section{Competing interests}

The authors declare that they have no competing interests.

\section{Publisher's Note}

Springer Nature remains neutral with regard to jurisdictional claims in published maps and institutional affiliations.

Received: 19 June 2017 Accepted: 20 November 2017

Published online: 02 December 2017

References

1. Wu CL, Raja SN. Treatment of acute postoperative pain. Lancet. 2011; 377(9784):2215-25.

2. Kehlet H, Dahl JB. The value of" multimodal" or" balanced analgesia" in postoperative pain treatment. Anesth Analg. 1993;77(5):1048-56.

3. Management ASoATFoAP. Practice guidelines for acute pain management in the perioperative setting: an updated report by the American Society of Anesthesiologists Task Force on acute pain management. Anesthesiology. 2012;116(2):248

4. Tallarida RJ. Drug synergism: its detection and applications. J Pharmacol Exp Ther. 2001;298(3):865-72.

5. Jones CK, Peters SC, Shannon HE. Efficacy of duloxetine, a potent and balanced serotonergic and noradrenergic reuptake inhibitor, in inflammatory and acute pain models in rodents. J Pharmacol Exp Ther. 2005;312(2):726-32

6. Lunn MPT, Hughes RAC, Wiffen PJ. Duloxetine for treating painful neuropathy, chronic pain or fibromyalgia. Cochrane Database Syst Rev. 2014;1

7. Woolf CJ. Pain: moving from symptom control toward mechanism-specific pharmacologic management. Ann Int Med. 2004;140(6):441-51. 
8. Ho K-Y, Tay W, Yeo M-C, Liu H, Yeo S-J, Chia S-L, et al. Duloxetine reduces morphine requirements after knee replacement surgery. Br J Anaesth. 2010; 105(3):371-6. https://doi.org/10.1093/bja/aeq158.

9. Nasr DA. Efficacy of perioperative duloxetine on acute and chronic postmastectomy pain. Ain-Shams J Anaesth. 2014;7(2):129.

10. Castro-Alves $\sqcup$, de Medeiros A, Neves SP, de Albuquerque CLC, Modolo NS, De Azevedo $\mathrm{V}$, et al. Perioperative Duloxetine to improve postoperative recovery after abdominal hysterectomy: a prospective, randomized, double-blinded, placebo-controlled study. Anesth Analg. 2016;122(1):98-104.

11. Bedin A, Bedin RAC, Vieira JE, Ashmawi HA. Duloxetine as an analgesic reduces Opioid consumption after spine surgery: a randomized, double-blind, controlled study. Clin J Pain. 2017;33(10):865-9.

12. Goldstein DJ, Lu Y, Detke MJ, Lee TC, lyengar S. Duloxetine vs. placebo in patients with painful diabetic neuropathy. Pain. 2005;116(1):109-18.

13. Derry S, Moore RA. Single dose oral celecoxib for acute postoperative pain in adult, Cochrance Database of Systemic Review 2013;22(10). Issue 3. Art. No: CD004233. doi:10.1002/14651858.cd004233. pub 4.

14. White PF. The changing role of non-opioid analgesic techniques in the management of postoperative pain. Anesth Analg. 2005;101(5S):S5-S22.

15. Sostres C, Gargallo CJ, Arroyo MT, Lanas A. Adverse effects of non-steroidal anti-inflammatory drugs (NSAIDs, aspirin and coxibs) on upper gastrointestinal tract. Best Pract Res Clin Endocrinol. 2010;24(2):121-32.

16. Hawkey C. COX-2 inhibitors. Lancet. 1999:353(9149):307-14.

17. Sinatra RS, Shen QJ, Halaszynski T, Luther MA, Shaheen Y. Preoperative rofecoxib oral suspension as an analgesic adjunct after lower abdominal surgery: the effects on effort-dependent pain and pulmonary function. Anesth Analg. 2004;98(1):135-40.

18. Rasmussen GL, Malmstrom K, Bourne MH, Jove M, Rhondeau SM, Kotey P, et al. Etoricoxib provides analgesic efficacy to patients after knee or hip replacement surgery: a randomized, double-blind, placebo-controlled study. Anesth Analg. 2005;101(4):1104-11.

19. Puura A, Puolakka P, Rorarius M, Salmelin R, Lindgren L. Etoricoxib premedication for post-operative pain after laparoscopic cholecystectomy. Acta Anaesthesiol Scand. 2006;50(6):688-93.

20. Clark R, Derry S, Moore RA. Single dose oral etoricoxib for acute postoperative pain in adult. The Cocharance Database Systemic Reviews. 2012;18(4):CD004309. doi:10.1002/14651858.CD004309. pub 3.

21. Agrawal NG, Porras AG, Matthews CZ, Woolf EJ, Miller JL, Mukhopadhyay S, et al. Dose proportionality of oral etoricoxib, a highly selective cyclooxygenase-2 inhibitor, in healthy volunteers. J Clin Pharmacol. 2001; 41(10):1106-10.

22. Liu W, Loo C, Chiu J, Tan H, Ren H, Lim Y. Analgesic efficacy of preoperative etoricoxib for termination of pregnancy in an ambulatory centre. Singap Med J. 2005;46(8):397.

23. Lierz $\mathrm{P}$, Losch $\mathrm{H}$, Felleiter P. Evaluation of a single preoperative dose of etoricoxib for postoperative pain relief in therapeutic knee arthroscopy: a randomized trial. Acta Orthop. 2012;83(6):642-7.

24. Sun Y-H, Dong Y-L, Wang Y-T, Zhao G-L, Lu G-J, Yang J, et al. Synergistic analgesia of duloxetine and celecoxib in the mouse formalin test: a combination analysis. PLoS One. 2013;8(10):e76603.

25. Bijur PE, Latimer CT, Gallagher EJ. Validation of a verbally administered numerical rating scale of acute pain for use in the emergency department. Acad Emerg Med. 2003;10(4):390-2.

26. Myles $P$, Wengritzky $R$. Simplified postoperative nausea and vomiting impact scale for audit and post-discharge review. Br J Anaesth. 2012; 108(3):423-9.

27. Happich M, Schneider E, Boess FG, Wilhelm S, Schacht A, Birklein F, et al. Effectiveness of duloxetine compared with pregabalin and gabapentin in diabetic peripheral neuropathic pain: results from a German observational study. Clin J Pain. 2014;30(10):875-85.

28. Onuțu AH. Duloxetine, an antidepressant with analgesic properties-a preliminary analysis. Rom J Anaesth Intensive Care. 2015;22(2):123-8.

29. Basbaum Al, Fields HL. Endogenous pain control systems: brainstem spinal pathways and endorphin circuitry. Annu Rev Neurosci. 1984;7(1):309-38.

30. Wang S-Y, Calderon J, Wang GK. Block of neuronal Na+ channels by antidepressant duloxetine in a state-dependent manner. J Am Soc Anesth. 2010;113(3):655-65.

31. Nakajima K, Obata H, Iriuchijima N, Saito S. An increase in spinal cord noradrenaline is a major contributor to the antihyperalgesic effect of antidepressants after peripheral nerve injury in the rat. Pain. 2012; 153(5):990-7.
32. Biddiss $E$, Knibbe TJ, McPherson A. The effectiveness of interventions aimed at reducing anxiety in health care waiting spaces: a systematic review of randomized and nonrandomized trials. Anesth Analg. 2014;119(2):433-48.

33. Kehlet H. Postoperative Opioid sparing to hasten RecoveryWhat are the issues? J Am Soc Anesthesiol. 2005;102(6):1083-5.

34. Recla JM. New and emerging therapeutic agents for the treatment of fibromyalgia: an update. J Pain Res. 2010;3(89-103):b4.

35. Rawal N, Viscusi E, Peloso PM, Minkowitz HS, Chen L, Shah S, et al. Evaluation of etoricoxib in patients undergoing total knee replacement surgery in a double-blind, randomized controlled trial. BMC Musculoskelet Disord. 2013;14(1):300.

36. Wheeler M, Oderda GM, Ashburn MA, Lipman AG. Adverse events associated with postoperative opioid analgesia: a systematic review. J Pain. 2002;3(3):159-80.

37. YaDeau JT, Brummett CM, Mayman DJ, Lin Y, Goytizolo EA, Padgett DE, et al. Duloxetine and subacute pain after knee Arthroplasty when added to a multimodal analgesic RegimenA randomized, placebo-controlled, tripleblinded trial. J Am Soci Anesth. 2016;125(3):561-72.

38. Lehmann TR, LaROCCA HS. Repeat lumbar surgery: a review of patients with failure from previous lumbar surgery treated by Spinal Canal exploration and lumbar spinal fusion. Spine. 1981;6(6):615-9.

\section{Submit your next manuscript to BioMed Central and we will help you at every step:}

- We accept pre-submission inquiries

- Our selector tool helps you to find the most relevant journal

- We provide round the clock customer support

- Convenient online submission

- Thorough peer review

- Inclusion in PubMed and all major indexing services

- Maximum visibility for your research

Submit your manuscript at www.biomedcentral.com/submit

) Biomed Central 